\title{
Article \\ VPB1 Encoding BELL-like Homeodomain Protein Is Involved in Rice Panicle Architecture
}

\author{
Mu Li *, Debao Fu, Tingting $X u$ and Changyin $W u$ *D
}

check for updates

Citation: Li, M.; Fu, D.; Xu, T.; Wu, C. VPB1 Encoding BELL-like

Homeodomain Protein Is Involved in Rice Panicle Architecture. Int. J. Mol. Sci. 2021, 22, 7909. https://doi.org/ $10.3390 /$ ijms 22157909

Academic Editors: Kiyosumi Hori, Matthew Shenton and Marcello Iriti

Received: 15 June 2021

Accepted: 20 July 2021

Published: 24 July 2021

Publisher's Note: MDPI stays neutral with regard to jurisdictional claims in published maps and institutional affiliations.

Copyright: (c) 2021 by the authors. Licensee MDPI, Basel, Switzerland. This article is an open access article distributed under the terms and conditions of the Creative Commons Attribution (CC BY) license (https:/ / creativecommons.org/licenses/by/ $4.0 /)$.
National Key Laboratory of Crop Genetic Improvement, Huazhong Agricultural University, Wuhan 430070, China; debaofu@webmail.hzau.edu.cn (D.F.); xtt8831@webmail.hzau.edu.cn (T.X.)

* Correspondence: limu@webmail.hzau.edu.cn (M.L.); cywu@mail.hzau.edu.cn (C.W.); Tel.: +86-136-3868-9237 (M.L.); +86-027-8728-1887 (C.W.)

\begin{abstract}
Inflorescence architecture in rice (Oryza sativa) is mainly determined by spikelets and the branch arrangement. Primary branches initiate from inflorescence meristem in a spiral phyllotaxic manner, and further develop into the panicle branches. The branching patterns contribute largely to rice production. In this study, we characterized a rice verticillate primary branch 1(vpb1) mutant, which exhibited a clustered primary branches phenotype. Gene isolation revealed that VPB1 was a allele of $R I$, that it encoded a BELL-like homeodomain (BLH) protein. VPB1 gene preferentially expressed in the inflorescence and branch meristems. The arrangement of primary branch meristems was disturbed in the $v p b 1$ mutant. Transcriptome analysis further revealed that VPB1 affected the expression of some genes involved in inflorescence meristem identity and hormone signaling pathways. In addition, the differentially expressed gene (DEG) promoter analysis showed that OsBOPs involved in boundary organ initiation were potential target genes of VPB1 protein. Electrophoretic mobility shift assay (EMSA) and dual-luciferase reporter system further verified that VPB1 protein bound to the promoter of OsBOP1 gene. Overall, our findings demonstrate that VPB1 controls inflorescence architecture by regulating the expression of genes involved in meristem maintenance and hormone pathways and by interacting with OsBOP genes.
\end{abstract}

Keywords: inflorescence architecture; BLH homedomain protein; branching pattern; verticillate primary branch; transcriptome analysis; hormone pathways

\section{Introduction}

Inflorescence is the clusters of flowers arranged on a stem, and it comprises a main branch and lateral branches with a complicated arrangement [1-3]. The inflorescence architecture of higher plants contributes not only to plant morphology but also to plant reproduction, and further affecting the final grain yield in crops [4]. The panicle-type inflorescences are characteristics of grasses such as maize (Zea mays) and rice (Oryza sativa) [5]. Maize has two types of inflorescences, male tassel and female ear, which are different in morphology and branching pattern [6]. Rice inflorescence, also known as 'panicle', during panicle development, and shoot apical meristem (SAM) is transformed into the inflorescence meristem (IM) after transition from vegetative phase to reproductive phase, IM successively generates the primary and secondary branch meristem (PBM and SBM), floret meristem (FM), and spikelet meristem [7]. The main stem of rice panicle has primary and secondary branches, which are arranged in a spiral phyllotaxy [8]. Thus, the panicle branching patterns determine rice panicle architecture and eventually affect grain yield in rice [9].

So far, a large number of genes involved in regulating inflorescence architecture in rice have been identified, such as LAX PANICLE1 (LAX1) and LAX2 participating in the formation of axillary meristem (AM) in rice [10,11] and ABERRANT PANICLE ORGANIZATION 1 (APO1) positively regulating the number of spikelets and primary branches and affecting the attributes of floral organs and the identity of flowers [12]. APO2 
has been reported to regulate the transition from rice vegetative growth to reproductive growth and to control the development of panicle branches, and it can directly interact with APO1 to control the inflorescence and flower development [13]. The functional loss of either FLORAL ORGAN NUMBER1 (FON1) or FON2 causes the enlargement of the floral meristem, thus resulting in the increased floral organs $[14,15]$. ABERRANT SPIKELET AND PANICLE1 (ASP1; also known as OsREL2) regulates different aspects of rice development and physiological responses, such as the development of panicles, branches, and spikelets [16,17]. FON2 and $A S P 1$ are involved in the negative regulation of stem cell proliferation in both inflorescence meristems and flowers [18]. TILLERS ABSENT1 (TAB1) plays an important role in initiating the rice axillary meristems, but this gene is not involved in maintaining the established meristem [19]. TAW1 regulates inflorescence development by enhancing the activity of inflorescence meristems to inhibit the transformation from inflorescence meristems to spikelet meristems [20]. Those above-mentioned genes mainly control the length and the number of branches and meristem maintenance. However, our knowledge of the genetic mechanisms underlying branching patterns including branch phyllotaxy and internode elongation in rice remains limited.

Interestingly, the three-amino-acid-loop-extension (TALE) class of homeoproteins falls into two subfamilies, KNOTTED1-like homeobox (KNOX) and BELL1-like homeobox $(B L H)$, which have been reported to control meristem formation and maintenance, organ position in plant, and organ morphogenesis [21]. For example, in Arabidopsis thaliana, two paralogous BLH genes, PENNYWISE (PNY) (also known as BELLRINGER (BLR), REPLUMLESS (RPL), or VAAMANA (VAN)) and POUND-FOOLISH (PNF), play significant roles in maintaining the SAM and the development of the inflorescence architecture [22-29]. Loss-of-function $P N Y$ gene causes the altered phyllotaxy, including irregular internode elongation, clusters of branches and flowers on the stem, and eventually reducing apical dominance [30]. Furthermore, PNY is involved in the establishment of normal phyllotaxis by repressing the expression of PME5 (pectin methylesterase) in the meristem and the maintenance of phyllotaxis by activating PME5 in the internode [31]. BLH proteins can interact with KNOX proteins to form heterodimer. For example, PNY interacts with the SHOOTMERISTEMLESS (STM) and BREVIPEDICELLUS (BP). The double mutant $b p / p n y$ exhibits synergistic phenotype of the short internodes interspersed with the long internodes and the increased branches [30]. The interaction between PNY and STM maintains the boundary between floral primordia and inflorescence meristem, and the SAM function in Arabidopsis requires both PNY and STM [32,33]. In addition, ChIP-seq results reveal that $P N Y$ interacts with many of the key genes regulating stem morphogenesis and controling the oriented growth by directly repressing organ boundary genes [34]. In maize, the two $B L H$ genes, BLH12 and BLH14, are close homologs of PNY and PNF, and double mutant blh12/blh14 causes abnormality in internode pattern and vascular bundles anastomosis as well as indeterminate branch formation in the tassel [35].

In rice, one $B L H$ gene $q S H 1$ is a main quantitative trait locus of seed shattering [36]. In addition, another $\mathrm{BLH}$ gene $\mathrm{SH} 5$ induces seed shattering by facilitating abscission-zone development and inhibiting lignin biosynthesis, and SH5 can interact with KNOX protein OSH15 to induce grain shattering by repressing lignin biosynthesis-related genes $[37,38]$. One recent study has reported that gene RI encoding a BLH transcription factor affects primary branch pattern mainly by regulating the arrangement and initiation time of the primary branch meristems, the $B L H$ gene family is essential for regulating inflorescence structure in plant [39]. However, the molecular mechanism by which these genes regulate the branch arrangement pattern remain largely unknown in rice.

In this study, we characterized the rice verticillate primary branch 1 (vpb1) mutant, which displayed a clustered primary branch phenotype. Gene isolation experiment revealed that $V P B 1$ was a allele of $R I$, and it encoded a BLH transcription factor. Further experiments demonstrated that $V P B 1$ negatively regulated the expression of OsBOP1 gene to construct panicle architecture in rice. Transcriptome analysis indicated that VPB1 was likely to negatively regulate the expression of genes involved in auxin hormonal pathways to form 
the normal inflorescence architecture. Our results provide new insights into the branching patterns in rice.

\section{Results}

\subsection{Inflorescence Phenotypes in Vpb1 Mutant}

To identify the key regulators that control panicle architecture formation in rice, we screened two recessive and allelic mutants which exhibited abnormal panicles from rice T-DNA insertion mutant library. We designated them as verticillate primary branch 1-1 (vpb1-1) and vpb1-2 (Figure S1). Compared with wild-type inflorescence, the vpb1 mutant inflorescence exhibited the clustered primary branch phenotype, indicating the primary branches are initiated in a verticillate manner (Figure 1A-D). Our findings are consistent with a previous report that mutant phenotype of $R I$ [39]. To investigate vpb1 inflorescence quantitatively, we counted the number of inflorescence branches in the wild type and mutant. The primary branches number of $v p b 1$ mutant panicle was increased by $26.8 \%$, and the secondary branches number was decreased by $32.8 \%$, compared to the wild-type inflorescence (Figure 1E,F). Quantitative analysis of vpb1 mutant panicle indicated that the length of rachis and the number grains of panicle were respectively reduced by $56.5 \%$ and $27 \%$ compared with wild types (Figure 1G,H). The clustered panicle appearance and the reduction in spikelet number in the vpb1 mutant might be attributable to the reduced rachis length and the decreased number of secondary branches. Moreover, the vpb1 mutants exhibited a defect in producing the inflorescence meristem.
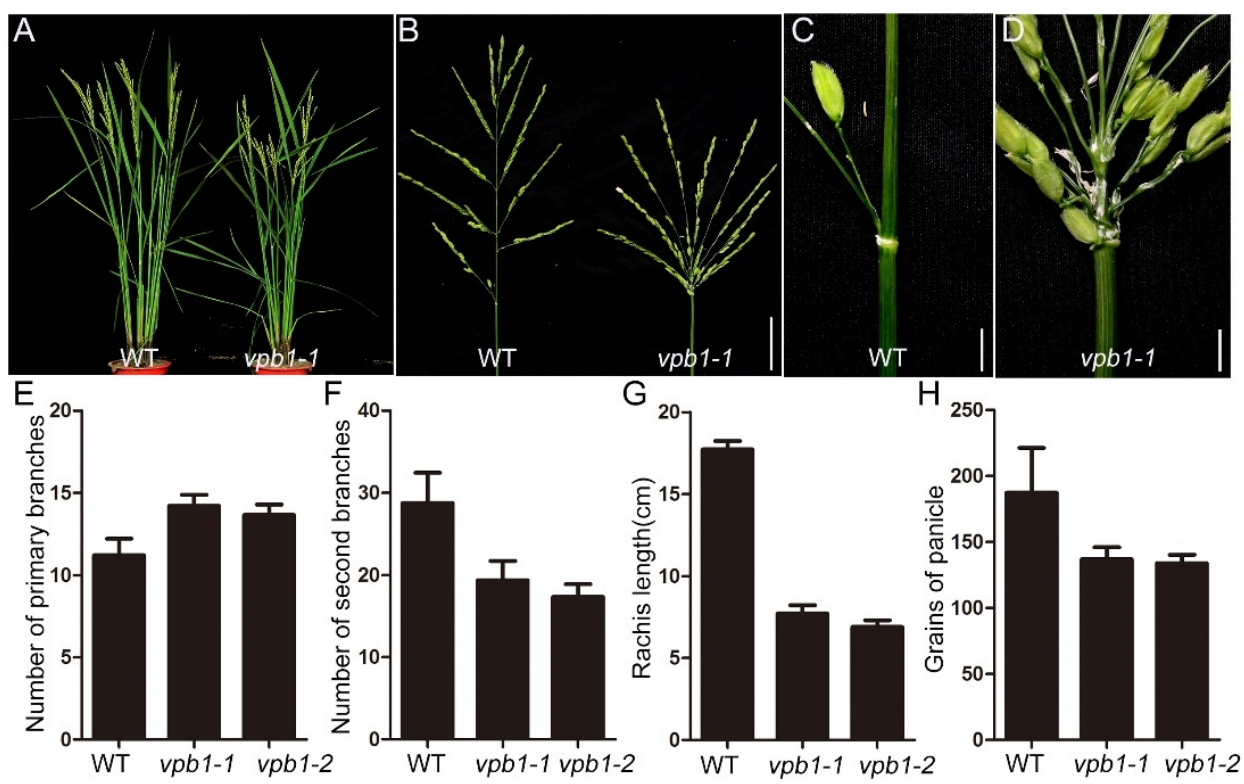

Figure 1. Phenotypic characterization of vpb1-1 mutant. (A) Mature wild-type plants (left) and the $v p b 1-1$ mutant (right). (B) Mature panicles of wild-type (left) and $v p b 1-1$ mutant (right). (C,D) Close-up view of the branch site of the primary branches in wild-type (C) and vpb1-1 mutant (D). (E-H) Quantitative traits of wild-type and $v p b 1$ mutant panicles. Vertical bars indicate standard deviations, $n=15$. (E) The numbers of primary branches in wild type and $v p b 1$ mutant. (F) The numbers of secondary branches in wild type and $v p b 1$ mutant. (G) Rachis length of wild type and vpb1 mutant. (H) The numbers of grains of panicle in wild type and $v p b 1$ mutant. Scale bars, $4 \mathrm{~cm}$ in (B); $2 \mathrm{~cm}$ in $(\mathbf{C}, \mathbf{D})$.

To further examine the defects of $v p b 1$ panicles, we used scanning electron microscope (SEM) to determine the time when the panicle development of vpb1-1 plants first differed from that wild type plants. SEM results indicated no significant morphological difference between $v p b 1$ and the wild-type SAMs in the vegetative stage and reproductive stage except the primary branch meristem (PBM) formation stage (Figure 2 and Figure S2). The wild 
type PBMs were initiated in a regular spiral pattern (Figure 2A). By contrast, vpb1 mutant PBMs were initiated in an irregular pattern and they might be simultaneously initiated from the inflorescence meristems (Figure 2D). The lateral view of PBMs showed that the height of the PBM cluster of $v p b 1$ was lower than that of wild type (Figure 2B,E). These results confirmed that the primary branch meristems of $v p b 1$ mutant displayed an abnormal arrangement on inflorescence meristem. We hypothesized that the disordered primary branch meristems might be caused by the abnormal development of inflorescence. To test this hypothesis, we especially used the paraffin section method to examine morphological characteristics of panicles, we found that the inflorescence meristem of $v p b 1$ mutant was extremely defective (Figure 2C,F). Therefore, we considered that the disordered phyllotactic pattern of $v p b 1$ inflorescence might be due to the disturbed arrangement of the primary branch meristems. VPB1 functioned as a determinant factor to regulate inflorescence meristem activity during panicle morphogenesis.
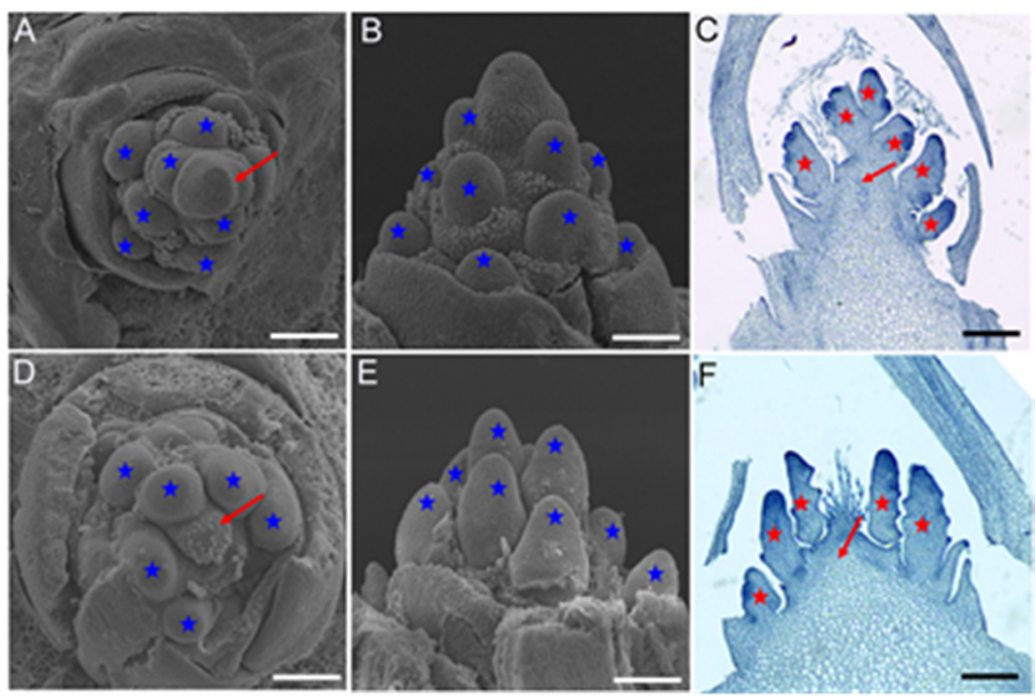

Figure 2. Morphological analysis of wild-type and $v p b 1$ inflorescence. (A,B) Scanning electron microscope (SEM) images of PBMs at their initiation stage in wild-type. (D,E) Scanning electron microscope (SEM) images of PBMs at their initiation stage in vpb1 mutant. (C,F) Paraffin section images showing the inflorescence of the wild type $(\mathbf{C})$ and $v p b 1(\mathbf{F})$. The arrow and asterisks indicate inflorescence and primary branch meristems, respectively. Scale bar, $100 \mu \mathrm{m}$.

\subsection{Map-Based Cloning of VPB1}

We constructed a mapping population by crossing the original vpb1 mutant with indica variety Dular. Of $1200 \mathrm{~F}_{2}$ plants, 288 exhibited a vpb1-like phenotype, and chi-square test results indicated that a segregation ratio of the $v p b 1$ mutant plants and wild-type plants was 1:3. These results demonstrated that the phenotype of vpb1 mutant was controlled by a recessive single gene. To clone gene VPB1 through a map-based approach, Primary gene mapping showed that VPB1 locus was located between the molecular markers RM3575 and RM7448 on chromosome 5, and we then fine-mapped the locus to a 38.5-kb region between markers RM3295 and IN22.30 (Figure 3A). Within this region, five genes were predicted in the Nipponbare genome (TIGR Rice Genome Annotation Database) (Table S1). PCRbased sequencing and bioinformatics analyses of this 38.5-kb region fragment revealed that a 433-bp DNA fragment was inserted into the second exon of the candidate gene LOC_Os05g38120 in vpb1-1 mutant to generate a premature stop codon, and that a 7-bp nucleotide deletion in the second exon in vpb1-2 led to amino acid frameshift (Figure S3). LOC_Os05g38120 composed of four exons and five introns encoded a homeodomain protein (Figure 3A and Table S1). To verify whether the clustered primary branch phenotype was caused by the DNA insertion and deletion in LOC_Os05g38120, a pair of gene-specific primers $\mathrm{P} 1$ and $\mathrm{P} 2$ were used to detect the genotype of the $\mathrm{F}_{2}$ population derived from the 
cross of $v p b 1$ with WT. Cosegregation analysis of an $\mathrm{F}_{2}$ population indicated that all the opb1-1 plants with homozygous DNA insertion showed the phenotype of the clustered primary branch, and the other plants without DNA insertion or with heterozygous DNA insertion showed normal panicle morphology (Figure 3B), and all the vpb1-2 plants with homozygous DNA deletion showed the phenotype of the clustered primary branch, and the other plants without DNA deletion or with heterozygous DNA deletion showed normal panicle morphology (Figure S3). Therefore, these results suggested that LOC_Os05g38120 was determined as the candidate gene of VPB1, which was a new allele of SH5/RI [37,39].

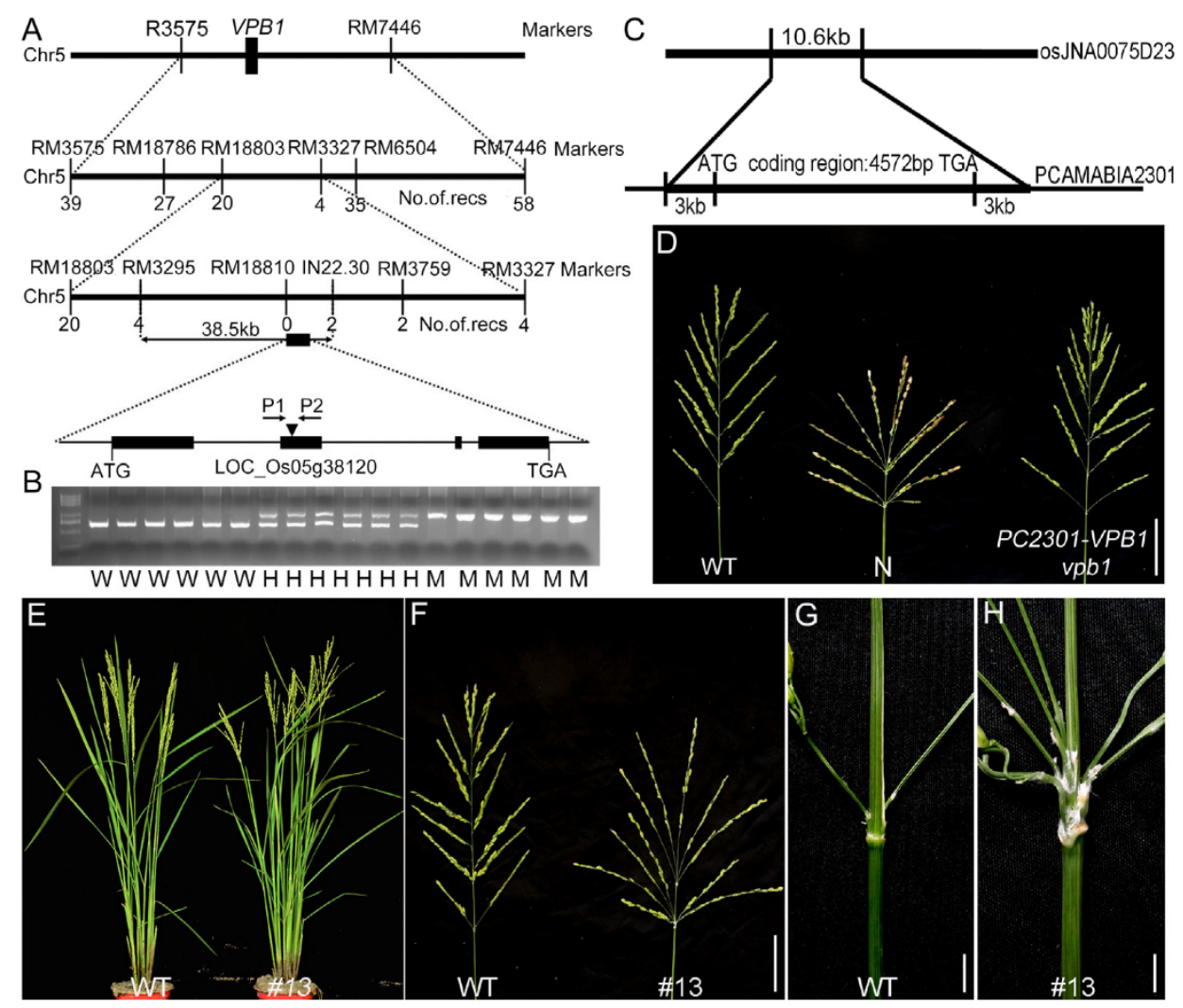

Figure 3. Positional cloning of the gene responsible for the $v p b 1$ mutation. (A) Fine mapping of the VPB1 on chromosome 5 . The $V P B 1$ locus was narrowed to a $\sim 38.5-\mathrm{kb}$ genomic DNA region between markers RM3295 and IN22.30. recs is the number of recombinants. The structure of VPB1, showing the mutation site of $v p b 1$. Closed boxes indicate the coding sequence, and lines between boxes represent introns. (B) Cosegregation analysis of a $F_{2}$ population derived from a cross of $v p b 1$ $x$ WT (ZH11) via PCR using the primers (P1, P2) shown in (A). M: mutant; H: hetero; W: wild type. (C) Schematic diagram of the pC2301-VPB1 construct. (D) Genetic complementation of $v p b 1$. $\mathrm{N}$ indicates negative control. Scale bar, $4 \mathrm{~cm}$. (E-H) Performance of $V P B 1$ positive and negative transgenic plants generated using the CRISPR/Cas9 strategy. (E) Mature wild-type plants (left) and the \#13 mutant (right). (F) Mature panicles of wild-type (left) and \#13 mutant (right). Scale bar, $4 \mathrm{~cm}$. $(\mathbf{G}, \mathbf{H})$ Close-up view of the branch site of the primary branches in wild-type $(\mathbf{G})$ and \#13 mutant $(\mathbf{H})$. Scale bar, $2 \mathrm{~cm}$.

To test VPB1 whether could complement the mutant phenotype, we constructed a vector. This vector fragment containing the coding sequence of VPB1 flanked by a 3000-bp upstream fragment of the start codon and a 3000-bp downstream fragment of the stop codon was cloned into pCAMBIA2301 (Figure 3C). This vector was transformed into vpb1 mutant callus, and 31 independent transgenic plants were obtained. The abnormal inflorescence phenotype of $v p b 1$ of these 31 transgenic plants was fully rescued by this constructed pC2301-VPB1, whereas that of 12 plants transformed with empty vector (negative control) remained unrescued (Figure 3D). Additonally, we generated function-deficient mutants in 
the ZH11 background using the CRISPR system (Figure S4) [40], and these mutants displayed reduced rachis length and verticillate primary branches (Figure 3E-H). Afterwards, we transformed vector pC1301S-VPB1-GFP with green fluorescent protein (GFP) fused to the $\mathrm{C}$ terminus of VPB1 into rice ZH11 (WT) callus, and obtained multiple independent lines overexpressing VPB1, their phenotypes were similar to those of wild-type (Figure S5). Moreover, in the young panicle, the expression of VPB1 was relatively lowly expressed in mutant, compared to that in wild-type plants (Figure S6A). The immunoblot assay with an anti-VPB1 antibody revealed that the accumulation of VPB1 protein in the young panicle $(2-3 \mathrm{~mm})$ was greatly reduced in $v p b 1-1$ and $v p b 1-2$ (Figure S6B). These results suggested that the mutation of VPB1 was responsible for abnormal panicle morphology of $v p b 1$.

\subsection{VPB1 Encodes a BELL1-Type Transcription Factor}

Bioinformatic analysis revealed that the amino acid sequence of VPB1 contains a conserved BELL domain, indicating that VPB1 is one member of the BLH family. Members of BLH family regulate many key developmental processes in plants $[21,27,35,41,42]$. Thirteen members of the BLH family have been identified in Arabidopsis and 17 members in rice [38]. These BLH proteins domain had three extra amino acids (Proline[P], tyrosine[Y], Proline [P]) between the first and the second helix (Figure S7A). To examine the relationship between VPB1 and other BLH proteins, we used amino acid sequences of VPB1 and other BLH proteins in rice and Arabidopsis to construct a phylogenetic tree (Figure S7B). The result revealed that the VPB1 protein was highly homologous to Arabidopsis PNY and PNF. Gene LOC_Os05g38120 has been reported to be SH5, phylogenetic analysis also revealed that the VPB1 was highly homologous to qSH1, and that both $\mathrm{SH} 5$ and qSH1 were responsible for the formation of seed abscission layer in rice [36,37]. Moreover, the alignment and motif analysis of VPB1 homologue in rice and Arabidopsis showed that VPB1 contained the intermediate BLH domain composed of SKY and BELL regions and the C-terminal homeobox domain, and it was relatively conservative in various plant species (Figure S7C).

\subsection{Expression Pattern of VPB1}

To reveal the role of $V P B 1$ in inflorescence development, we explored its expression pattern. The qRT-PCR analysis indicated that VPB1 was expressed in all tested tissues, including young leaf, mature leaf, leaf sheath, panicle, root, and stem; especially, it was expressed more highly in panicle than in other tissues (Figure 4A). RNA in situ hybridization further showed that VPB1 transcripts were detectable at different inflorescence development stages in wild-type, and that VPB1 was highly expressed in shoot apical meristem, primary and secondary branch meristem (Figure $4 \mathrm{~B}, \mathrm{C}, \mathrm{E}, \mathrm{F})$. This agrees with the results by Ikeda et al. (2019) [39]. As expected, VPB1 expression was hardly detectable when sense probe was used as a negative control (Figure $4 D, G$ ). The expression pattern analysis of both $V P B 1$ suggested that the VPB1 gene played a critical role in establishing and maintaining meristem in rice.

\subsection{Subcellular Localization and VPB1 Transcriptional Activity}

Consistent with the function of VPB1 as a transcription factor, through the subcellular localization prediction tool Plant-mPLoc [43], VPB1 was predicated to be located in the nucleus. To test this prediction, VPB1 was fused with YFP, and Ghd7 (a nuclear protein) was fused with cyan fluorescent protein (CFP). The obtained two fusion plasmids were transiently expressed in rice protoplasts, and the fluorescence signal assay indicated that VPB1 and Ghd7 were co-localized to the nucleus (Figure 5A), suggesting that VPB1 was a nuclear protein. 

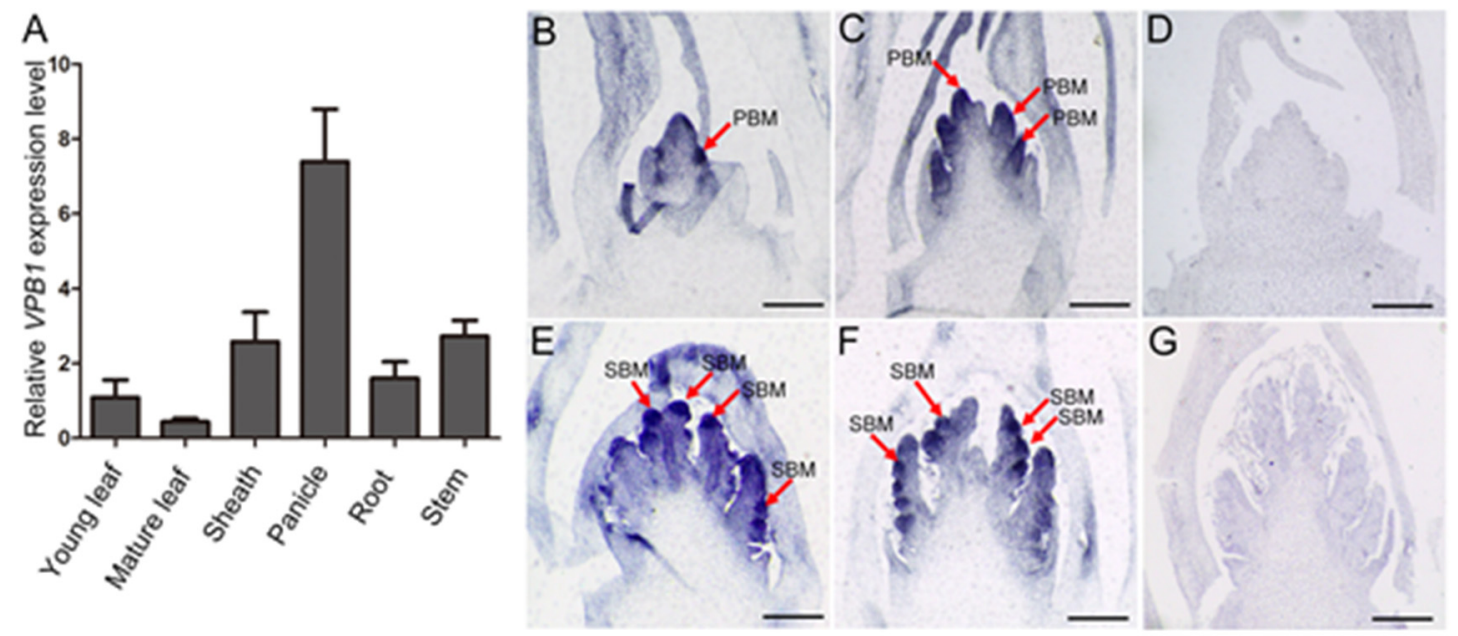

Figure 4. Expression pattern of VPB1. (A) RT-qPCR of organ-specific VPB1 expression in WT plants. Including young leaf, mature leaf, sheath, panicle (1-2 mm), root, stem. Data are mean $\pm \mathrm{SD}$ ( $\mathrm{n}=3$ biological replicates). (B-G) In situ hybridization of VPB1. (B) Whole a developing inflorescence at the stage of SAM; (C) Whole a developing inflorescence at the stage of primary branch meristem (PBM) differentiation; $(\mathrm{E}, \mathrm{F})$ Whole a developing inflorescence at the stage of secondary branch meristem (SBM) differentiation. (D,G) Sense probe as control. The red arrow points to the branch meristem. Scale bars, $100 \mu \mathrm{m}$.

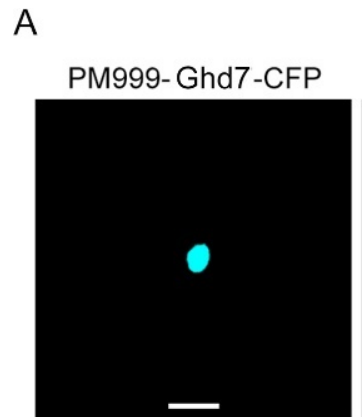

Bright

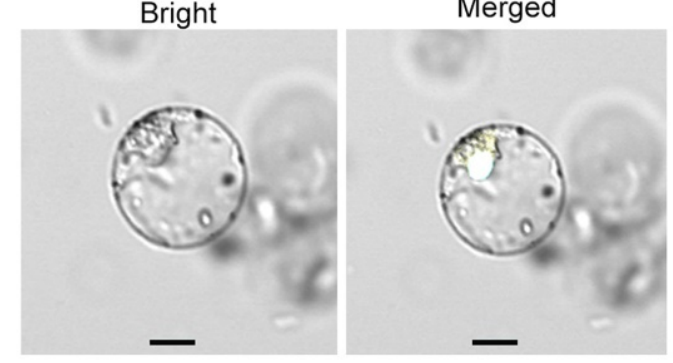

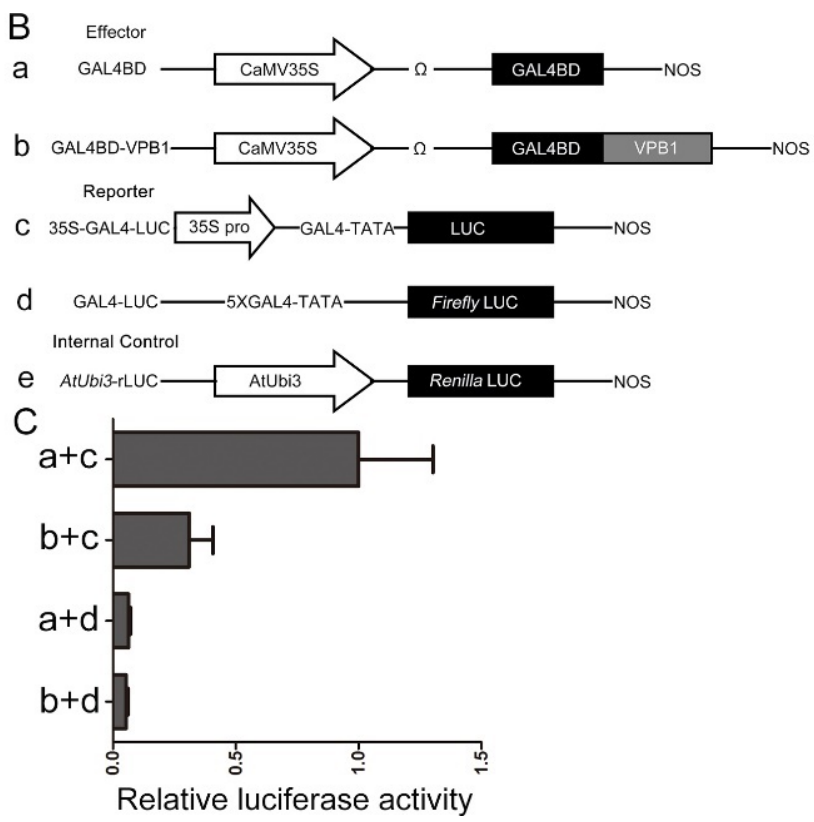

Figure 5. Subcellular localization and transcription activity of VPB1. (A) Subcellular localization of VPB1 protein. The VPB1-YFP fusion protein co-localized with the Ghd7 nucleus marker in rice protoplasts. Scale bars, $10 \mu \mathrm{m}$. (B) Scheme of the constructs used in the protoplast co-transfection assay. (C) Transcriptional activity assay of VPB1. The activity of 35S-GAL4-LUC and GAL4-LUC was used as the reporter, and rLUC activity was used as an internal control. The $\mathrm{fLUC} / \mathrm{rLUC}$ ratio represents the relative luciferase activity. Data are mean $\pm \mathrm{SD}$ ( $n=3$ independent replicates).

We next investigated the transcriptional activity of VPB1 using a dual-luciferase reporter system. We constructed an effector GAL4BD-VPB1, and the firefly luciferase gene driven by CaMV35S enhancer contained five copies of the GAL4 binding element, and it was used as a reporter, and the renilla luciferase gene driven by a AtUbi3 promoter was used as the internal control (Figure 5B). The results showed that the effector GAL4BD-VPB1 had significantly lower relative luciferase activity than the GAL4BD, but no significant difference in relative luciferase activity was observed between the reporter GAL4-fLUC 
and the GAL4BD (Figure 5C). Based on this result, we concluded that VPB1 could actively mediate transcriptional repression.

\subsection{VPB1 Affects the Expression of Genes Involved in Inflorescence Development and Hormone Pathways}

To reveal the molecular mechanism of inflorescence development in vpb1 mutant, we analyzed gene expression levels in the young panicle (1-2 mm) of vpb1-1 mutant and wild type plants at the stage of PBM initiation by RNA-Seq with $Q$ value $\leq 0.05$ and fold change $\geq 1.5$ as the cutoff criteria. We identified differentially expressed genes (DEGs) between wild type and mutants in three biological replicates. A total of 2028 genes were upregulated, and 2418 genes were downregulated in vpb1-1 mutant, compared with wild type (Table S2 and Figure 6A,B). Further gene ontology (GO) analyses revealed that these DEGs were enriched in multiple biological processes, including transcription regulation, plant hormone signal transduction, flower development, shoot system development regulation, meristem maintenance, internode patterning, organ growth, and metabolism processes (Figure 6C), suggesting that VPB1 participated in a complex regulation network of rice inflorescence development.

Auxin signaling and transport have been reported to be important determinants of inflorescence development in Arabidopsis [34]. Our DEG analysis revealed that VPB1 mainly participated in the auxin pathway and affected the genes related to meristem activity and inflorescence development. For example, genes OsMADS1, OsMADS3, OsMADS6, OsMADS8, and OsMADS58 have been reported to interact with each other to promote flower development, which is very important for the maintenance of flower meristem identity and the formation of flower organ [44], and genes GNP1, OsNPY2, SHAT1, FON1, ASP1, SHO1, OsSNB, and OsPIL1 are associated with the abscission zone development, meristem activity and fate, internode patterning, and inflorescence morphology [18,45-48]. To verify RNA-seq results, qPCR was used to analyze auxin pathway-related 7 genes and the above-mentioned 15 genes in the young panicle $(2 \mathrm{~mm})$ of WT and vpb1 plants. Our data indicated that the results of RNA-seq and qPCR were consistent, seven ARFs genes in the auxin pathway were strongly upregulated in $v p b 1$ mutant at young panicle stage (Figure 7A), and MADS-box genes and eight genes mainly involved in the maintenance of meristem activity were significantly different between wild type and $v p b 1$ mutant (Figure 7B). Taken together, RNA-seq results indicated that VPB1 ensured the formation of normal panicle architecture by regulating the expression of the genes related to auxin pathways and inflorescence meristem development.

Results indicated that VPB1 suppressed the expression of OsBOP1.

\subsection{VPB1 Negatively Regulates OsBOP1 Expression}

Evidence suggests that the BEL-type proteins regulate downstream target gene transcription by recognizing a core motif of these genes' promoters in Arabidopsis [49]. In our study, VPB1 encoded BLH proteins belonging to TALE family. Thus, to identify potential target genes of VPB1 protein, we downloaded TALE family binding core motifs (TFmatrixID_0278, Figure 8A) from PlantPAN 3.0 website [50], and we screened RNAseq-obtained DEGs containing the core motifs from the upstream $2 \mathrm{~kb}$ promoter regions of DEGs with MEME FIMO [51]. The results revealed that a total of 682 DEGs with core motifs were screened, including 309 upregulated and 373 downregulated genes (Table S3). Since VPB1 was transcriptional repressor, we further analyzed these 309 upregulated genes, and we found that genes $O s B O P$ genes were related to meristem development. Therefore, we speculated that $O s B O P s$ might be a potential target gene of $V P B 1$. 


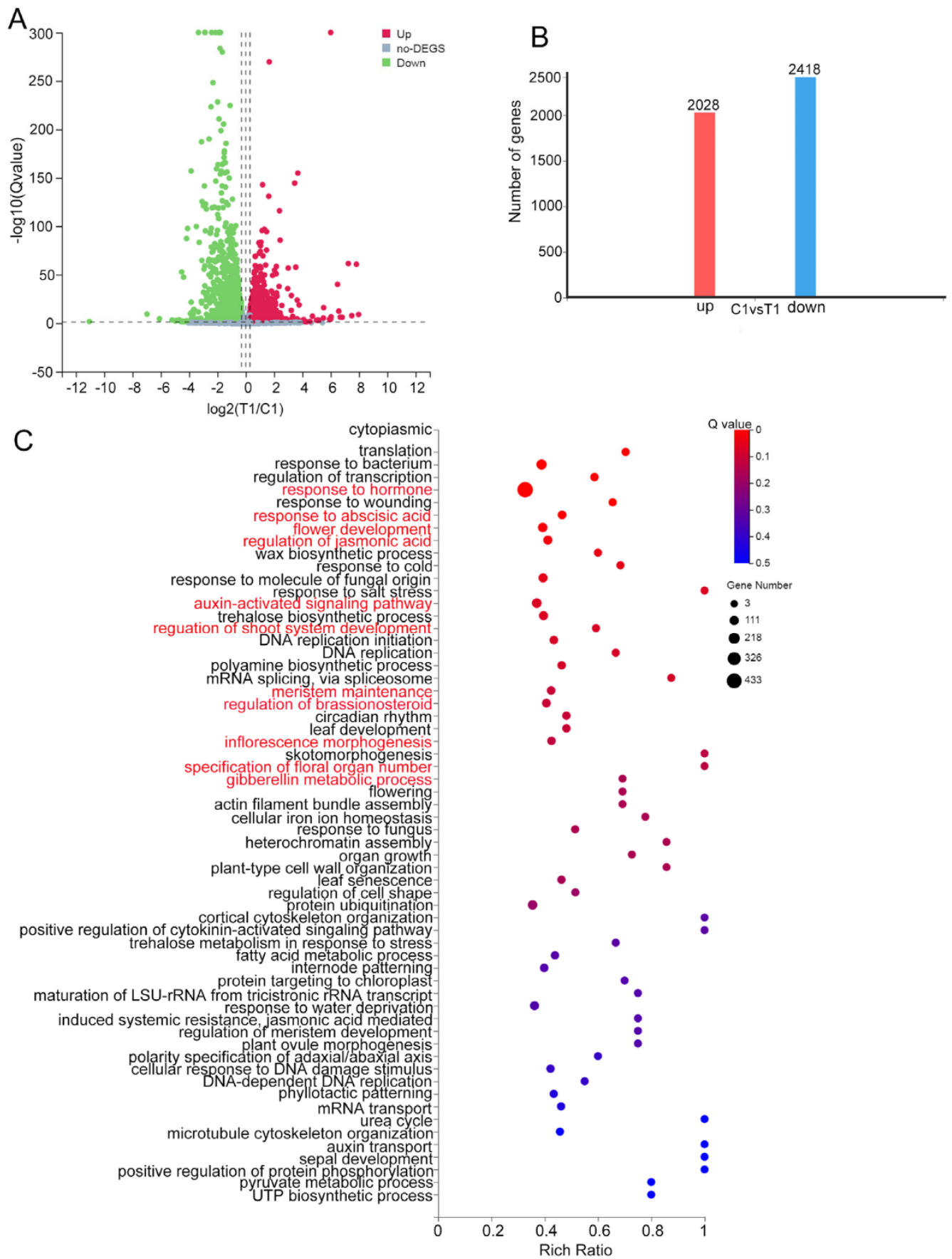

Figure 6. Differentially expressed genes statistics and GO analysis. (A) Volcano plots were used to visualize RNA sequencing (RNA-Seq) data. Each point corresponds to a reference sequence (Ref Seq) Gene. Red and green represent upregulated and downregulated genes in vpb1 lines compared with WT. T1: Mutant treatment group, C1: Wild type control group. (B) Statistics of the number of differentially expressed genes. Red represents upregulated DEGs, blue represents downregulated DEGs. (C) Gene ontology (GO) analysis functional categories of genes that differed in abundance between $v p b 1$ and WT. Biological pathways related to hormone signaling and inflorescence architecture are indicated on the left and marked in red. Points of different color and size represent gene numbers. 

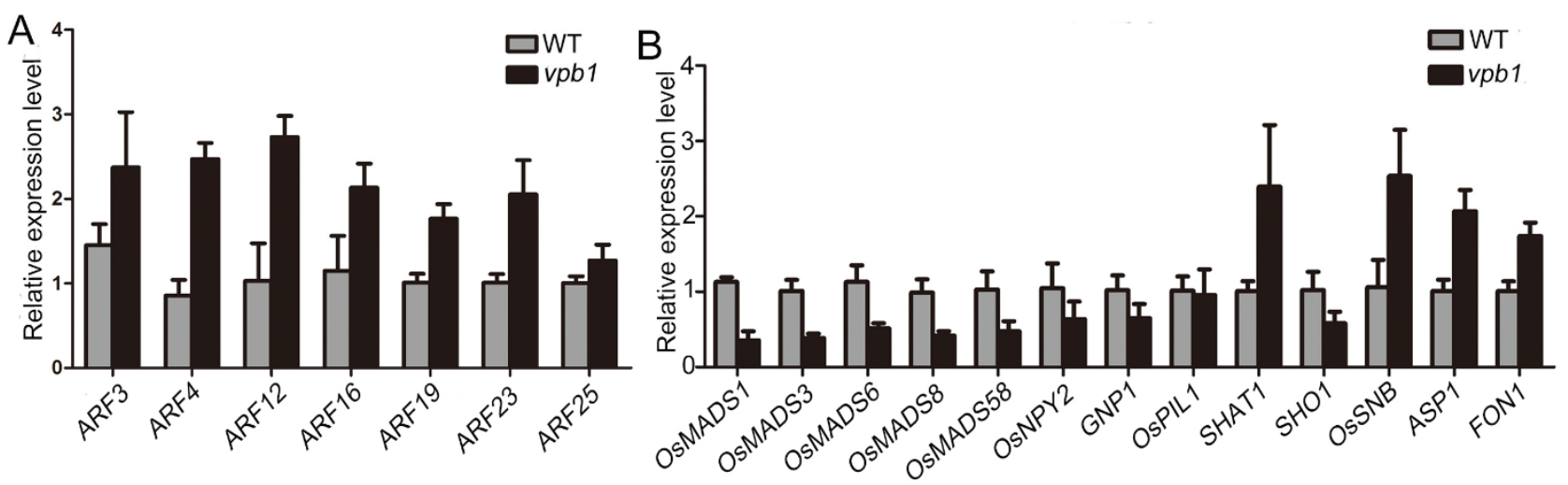

Figure 7. VPB1 regulates genes involved in hormone signaling and meristem maintenance. (A) Expression analysis of the auxin responsive factor genes in WT and $v p b 1$ young panicles. Data are mean $\pm \mathrm{SD}$. $(n=3$ biological replicates). (B) Expression analysis of the related to meristem maintenance genes in WT and $v p b 1$ young panicles. Data are mean \pm SD. ( $n=3$ biological replicates).
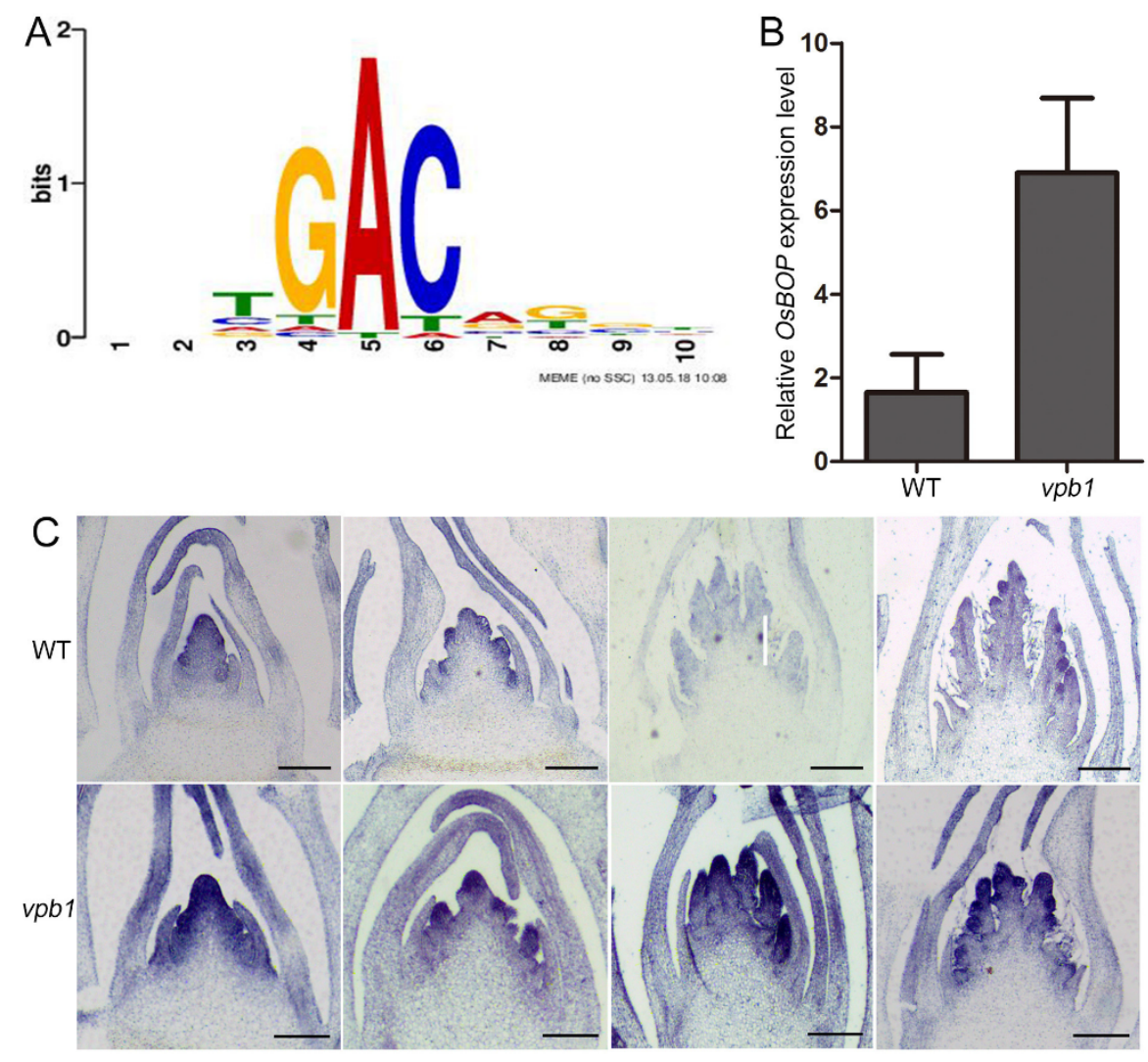

Figure 8. VPB1 negatively regulates OsBOP1 expression. (A) Putative TFBS for VPB1. (PlantPan3.0: http:/ / plantpan.itps.ncku.edu.tw / index.html (accessed on 21 November 2020). (B) RT-qPCR analysis of OsBOP1 expression in WT and $v p b 1$ young panicles $(2 \mathrm{~mm})$. Data are mean $\pm \mathrm{SD}$. $(n=3$ biologically independent replicates). (C) In situ hybridization of OsBOP1 mRNA in WT and vpb1 in different stages of inflorescence development. Scale bars, $100 \mu \mathrm{m}$.

To test whether the OsBOP expression was directly regulated by VPB1 protein, we first compared the expression patterns of OsBOP1 in WT and $v p b 1$. The qRT-PCR analysis revealed that in young panicle (1-2 $\mathrm{mm})$, the OsBOP1 expression level was higher in $v p b 1$ than in WT (Figure 8B). Consistently, in situ hybridization experiments detected a broader expression of OsBOP1 in the SAM, PBMs and SBMs in $v p b 1$ mutant plants than in WT plants with its expression expanded throughout the PBMs and SBMs (Figure 8C). These 
Then, we examined the ability of VPB1 protein to bind to the promoter region of $O s B O P s$ using electrophoretic mobility shift assay (EMSA). Promoter analysis revealed that OsBOPs contained TALE family core motif (Table S3). Thus, OsBOP1 promoter fragment (50 bp) containing the 10-bp sequence CATGACAGAT and OsBOP2 promoter fragment (50 bp) containing the 10-bp sequence TATGACAGAT were selected for EMSA. We constructed MBP protein and MBP-VPB1 fusion protein, and by using them, we detected the shifted bands which combined MBP-VPB1 fusion protein and the probes with CATGACAGAT and TATGACAGAT in the OsBOPs promoter region, but not the shifted bands of MBP protein (Figure 9A).

A
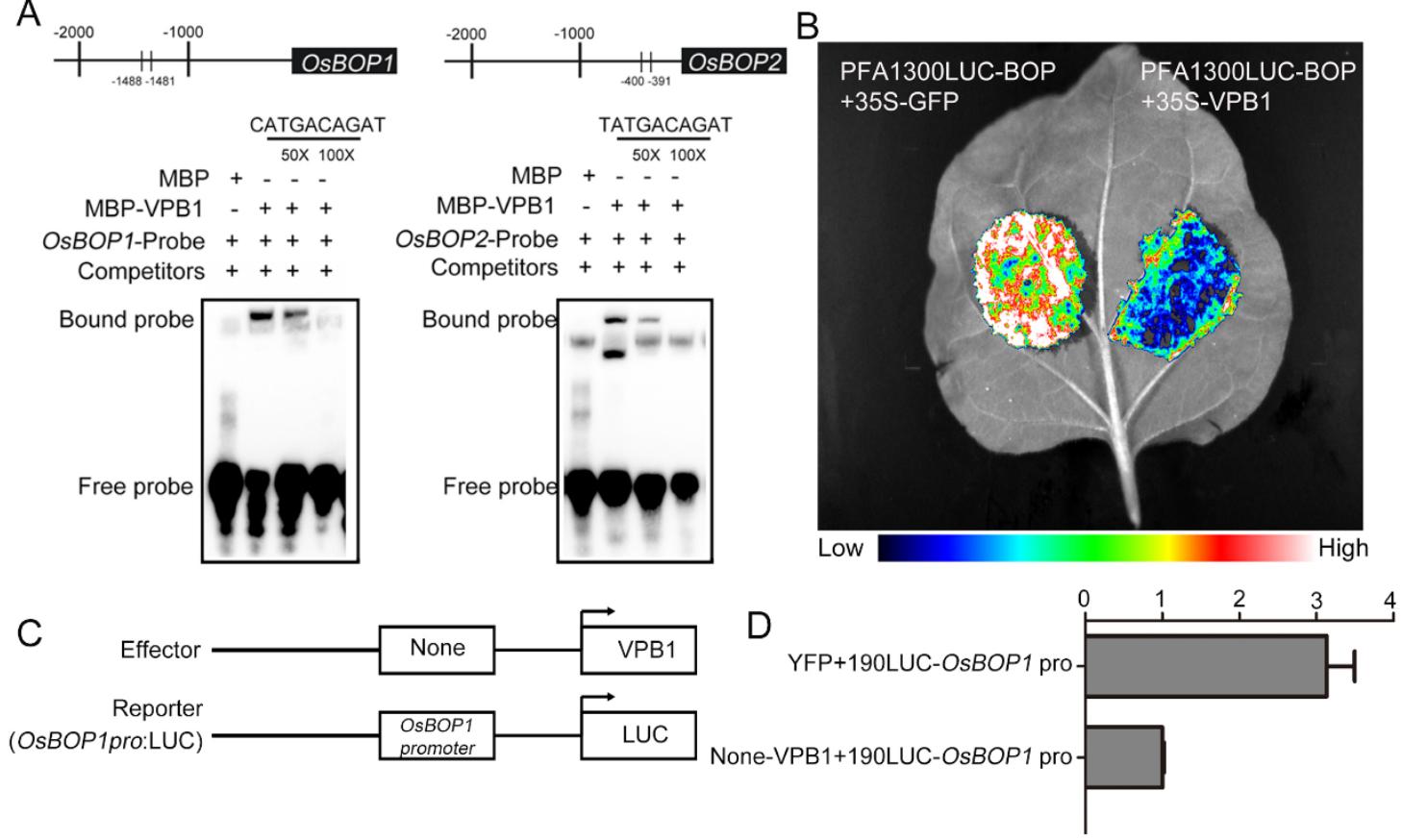

Figure 9. VPB1 is the transcriptional repressor of OsBOP1. (A) Schematic diagram of the OsBOP1/2 promoter showing the potential VPB1 binding sites and EMSA of MBP and MBP-VPB1 recombinant proteins incubated with biotin-labeled probes of $O s B O P 1$ and $O s B O P 2$. Numbers above the diagram indicate the distance away from ATG. Competition for binding was performed using $50 \times$ and $250 \times$ competitive probes; MBP was used as a negative control. (B) Analysis of the binding ability of VPB1 with the OsBOP1 promoter transiently expressed in tobacco leaves by transient expression regulation assays, showing that VPB1 protein suppresses the expression of OsBOP1. (C) Scheme of the constructs used in the protoplast dual luciferase reporter assays. (D) Dual luciferase reporter assays in rice protoplasts shows that the VPB1 protein suppresses the expression of LUC gene through binding to the OsBOP1 promoter. Data are mean $\pm \mathrm{SD}$ ( $n=3$ independent replicates).

Additionally, we attempted to confirm VPB1 binding ability in Nicotiana benthamiana leaves using transient expression assays. Strong signals were detected in tobacco leaves when proOsBOP1: LUC was transformed, but only weak signals were detected when VPB1 protein was coexpressed with proOsBOP1: LUC (Figure 9B). This result indicated that VPB1 could directly bind to the OsBOP1 promoter to repress its expression. Finally, dual luciferase reporter assays in rice protoplasts showed that VPB1 could suppress the expression of LUC gene by binding to the OsBOP1 promoter (Figure 9C,D). In addition, we created a double mutant vpb1/osbop1, and found that the morphology of osbop1 single mutant plants was normal, but the vpb1/osbop1 double mutant plants exhibited similar phenotype with the $v p b 1$ mutant plant, indicating inflorescence architecture defects caused by vpb1 mutation were not rescued (Figure S8). Importantly, our data demonstrated that $V P B 1$ controled the inflorescence development by directly negatively regulating the expression of $O s B O P$ genes. 


\section{Discussion}

\subsection{VPB1 Regulates the Initiation and Arrangement of Primary Branch Meristems}

The normal development of the primary branch meristems is important for the inflorescence architecture of rice [8]. Morphological analysis at the stage of primary branch development indicated that in $v p b 1$ mutant plants, the initiation timing and arrangement of the primary branch meristems were abnormal, that inflorescence meristem was damaged, and that the activity of the inflorescence meristem was reduced, resulting in the clustered primary branch meristems, but the secondary branch meristems and spikelets were less affected, suggesting that VPB1 mainly maintained the activity of inflorescence meristem and regulated the phyllotactic pattern of the primary branches. Similarly, we found that VPB1 was expressed in shoot apical meristem in the early stage of panicle development, and specifically expressed in the primary and secondary branch meristems. Moreover, $P N Y$ gene is essential for the formation of meristems and the maintenance of activity in Arabidopsis [23]. Collectively, these observations indicated that VPB1 gene ensured the initiation and fine arrangement of the branch meristem by maintaining the activity of the inflorescence meristem.

\subsection{VPB1 Belongs to a Functionally Conserved Gene Family}

Numerous previous studies have reported that $B L H$ genes influence many aspects of plant morphology and typically maintain the meristem activity essential for organ formation $[21,35,39,42]$, but little is known about their involvement in the regulation of panicle morphology development in rice. In this study, we isolated the key regulator VPB1 encoding a BLH protein, and we found that the functional loss of VPB1 resulted in clustered primary branches and short rachis. Thus, it could be concluded that VPB1 played an important role in inflorescence formation. Positional cloning revealed that VPB1 was identical to the previously reported $R I$ gene which was identified as the ortholog of Arabidopsis PNY and maize BLH12/14, indicating that VPB1 was involved in forming normal inflorescence architecture by regulating the phyllotactic pattern $[30,35,39]$. These findings supported that the BLH transcription factors had partially conserved functions in regulating the inflorescences in dicots and monocots.

\subsection{The VPB1 Gene Participates in a Complex Molecular Pathway to Regulate Panicle Development}

TALE genes are well-known to play critical roles in regulating inflorescence architecture by affecting plant hormones [21]. For example, in Arabidopsis, PNY has been reported to directly target the auxin transport- and signaling pathway- related genes [34]. The mutually combined transcriptional regulators ETT, IND, BP, RPL, and SEU regulate the transcription of genes responsible for inflorescence development and auxin polar transport to facilitate proper auxin distribution in inflorescence in brassicaceae [52]. Our RNA-seq results showed that VPB1 was a powerful regulatory protein, and it significantly affected the genes related to the auxin, brassinosteroid (BR), abscisic acid, and gibberellin pathways (Figure 6C). Interestingly, CPB1 (a new allele of D11) has been reported to encode a cytochrome protein $\mathrm{P} 450$ which is involved in BR biosynthesis pathway, and cpb1 mutant plants also exhibit a clustered primary branch phenotype, compared to wild type plants [53]. Therefore, we guessed that VPB1 might regulate the expression of CPB1 gene during inflorescence development. We further analyzed the expression levels of auxin-related genes $(A R F s)$ in WT and $v p b 1$ young panicles by qRT-PCR (Figure 7A). Our qRT-PCR results were consistent with RNA-seq data. Based these results, we speculated that the distribution or content of auxin in the vpb1 mutant has changed, reducing the activity of the inflorescence meristem, and ultimately leading to the disorder of the initiation and arrangement of the branch meristem, the mechanism underlying VPB1 regulation of branch arrangement in relation to auxin action is important issues to be resolved in our future studies.

Our data indicated the phenotype of the vpb1 mutant plant might be caused by the reduced inflorescence meristem activity. Notably, our DEG analysis revealed that VPB1 regulated multiple genes involved in the meristem identity maintenance and inflorescence 
development. The expressions of these genes exhibited significant difference between wild type and VPB1 mutant (Figure 7B). The possible reason for such difference might lie in that the VPB1 made these genes unable to be normally expressed in meristems, thus causing the failure in maintaining inflorescence meristem growth. Alternatively, the inhibition of inflorescence meristem activity might be associated with a change in cell wall components, as reported in Arabidopsis [31]. The regulation mechanism by which the change in cell wall components affects meristem activity remains to be further investigated in future studies.

\subsection{VPB1 Regulates Inflorescence Development by Directly Binding to OsBOP1}

This study indicated that VPB1 was a transcriptional repressor. Our RNA-seq data of vpb1 young panicle revealed that a total of 2028 genes were upregulated (Table S2). Of these upregulated genes, some genes were found to contain the conserved TALE core motifs, such as $O s B O P$ genes. Previous studies have shown that $B O P 1$ and its highly homologous gene, $B O P 2$, are involved in floral patterning, abscission zone formation, and bract suppression, and control of axillary bud growth and inflorescence development in plants [54-56]. Three $B O P$ genes (OsBOP1, OsBOP2, and OsBOP3) in rice determine the leaf sheath: blade ratio by activating proximal sheath differentiation and suppressing distal blade differentiation, and these three genes are related to the microRNA156/SPL pathway [57]. Pioneering work in Arabidopsis has shown that PNY directly binds to BOP1, BOP2, and KNAT6 to inhibit their expressions, eventually to regulate inflorescence development [49,58]. Our dual-luciferase reporter system and EMSA confirmed that the expressions of these genes were repressed by VPB1, and that the expression level of OsBOP1 involved in the boundary organ initiation pathway was significantly upregulated in $v p b 1$ mutant young panicle. Consistently, RNA in situ hybridization assay indicated that VPB1 suppressed expression of OsBOPs. However, inflorescence architecture defects caused by vpb1 mutation were not rescued in the vpb1/osbop1 double mutant plants. Previous research has shown that OsBOP genes in rice redundantly control leaf development [57]. Considering this, we speculated that three $O s B O P$ genes might also redundantly control inflorescence architecture, in addition to regulating OsBOP1, VPB1 might also regulate other downstream target genes to control panicle development. Based on these findings, it could be concluded that VPB1 protein could directly interact with the promoter of these OsBOP genes and suppress their transcriptions to maintain the normal development of inflorescence meristem. The genetic relationship between $V P B 1$ and $O s B O P$ genes will be the focus of our future research.

\subsection{The Role of BLH-KNOX Dimer Functions in Inflorescence Development}

The interaction between BLH and KNOX homeobox proteins to form heterodimers has been widely reported [32,59], and these two proteins can form complexes and participate in meristem maintenance and the plant growth and development regulation. For example, PNY physically interacts with BP to form BP-PNY complex required by normal inflorescence architecture development [30]. Our study found VPB1 interacted with OSH1 and OSH15 (Figure S9), which are consistent with previously reported that SH5 can interact with OSH15 protein [38]. These findings indicated that the mechanism by which BLH and KNOX transcription factors regulated inflorescence architecture in rice was similar to that in Arabidopsis. Overall, VPB1 interacted with the typical genes of the KNOX family $\mathrm{OSH} 1 / \mathrm{OSH} 15$ to form a protein complex, thus regulating panicle architecture development in rice.

Notably, the vpb1 mutant identified in this study represents a new allele of the rice gene $S H 5$ regulating seed shattering [37,38]. Based on these results, we speculated that the $B L H$ genes may play different roles and participate in different biological processes across rice varieties. Thus, identifying favorable alleles of VPB1 will enrich our knowledge of panicle architecture in rice. 


\section{Materials and Methods}

\subsection{Plant Materials and Growth Conditions}

This study used Oryza sativa subspecies Japonica "Zhonghua11" (ZH11) as rice materials. The mutant $v p b 1$ was derived from our T-DNA insertional mutant library (http:/ / rmd.ncpgr.cn/ (accessed on 13 July 2016)). Plants were cultivated under natural long day (LD) conditions during the rice growing season in the experimental field of Huazhong Agriculture University, Wuhan, China, and they were moved to a greenhouse during the winter. All transgenic plants were grown under similar growth conditions.

\subsection{Scanning Electron Microscopy}

In scanning electron microscopy assay, young panicles from WT and vpb1-1 mutants at different developmental stages were dissected, and immediately fixed in solution containing $70 \%$ ethanol, 3.7\% formaldehyde, and $5 \%$ acetic acid for $24 \mathrm{~h}$ at $4{ }^{\circ} \mathrm{C}$ overnight. Tissues were dehydrated with a concentration series of ethanol from $25 \%$ to $100 \%$ and air-dried. After ethanol dehydration and drying, the samples were coated with gold by using an E-100 ion sputter, and then observed under a scanning electron microscope (S570, Hitachi, Tokyo, Japan).

\subsection{Histological Sectioning}

For paraffin sectioning, young panicles from wild type plant and vpb1-1 mutant plant at different developmental stages were dissected. The samples were fixed in FAA solution at ratio of formaldehyde: glacial acetic acid: ethanol $=1: 1: 18, \mathrm{v} / \mathrm{v} / \mathrm{v}$ at $4{ }^{\circ} \mathrm{C}$ for $24 \mathrm{~h}$. Subsequently, the samples were dehydrated and cleared in a graded series of ethanol and xylene. The samples were microtome sectioned at the thickness of $5 \mu \mathrm{m}$. Afterwards, the sections were stained with $0.5 \%$ toluidine blue at room temperature for $30 \mathrm{~min}$, and they were observed with a light microscope.

\subsection{Map-Based Cloning of VPB1}

To determine the vpb1 locus, we crossed the vpb1 mutant with indica variety Dular to obtain $F_{1}$ plants, and generated an $F_{2}$ mapping population through $F_{1}$ self-crossing. For rough mapping, $15 \mathrm{~F}_{2}$ vpb1 plants and 15 WT plants were used to establish two DNA pools. A total of 1200 independent individuals from the $F_{2}$ population were adopted for fine mapping. The five genes were screened from $38.5 \mathrm{~kb}$ regions between two genetic markers on the physical map. Genotyping analysis of the vpb1 co-segregating population was performed by PCR with the primers VPB1-CS-P1 and VPB1-CS-P2. PCR was conducted as follows: pre-denaturation at $95^{\circ} \mathrm{C}$ for $5 \mathrm{~min}$, followed by 32 cycles of denaturation $95{ }^{\circ} \mathrm{C}$ for $45 \mathrm{~s}$, annealing at $58{ }^{\circ} \mathrm{C}$ for $45 \mathrm{~s}$, and extension at $72{ }^{\circ} \mathrm{C}$ for $1 \mathrm{~min}$. Subsequently, PCR products were verified by sequencing.

\subsection{Plasmid Construction and Rice Transformation}

To prepare the complementation vector, we extracted ZH11 BAC clone OSJNA0075D23, and used PCR to amplify this clone into three fragments and obtained a about $10.6 \mathrm{~kb}$ foreign fragment consisting of the entire VPB1 gene coding region, one $3 \mathrm{~kb}$ fragment in front of the ATG, and another $3 \mathrm{~kb}$ fragment behind the stop code. We connected this foreign fragment to the PCAMBIA2301 vector by the Gibson Assembly Master Mix (NEB, catalog, E2611L). For overexpression of VPB1, the full-length cDNA sequence of $V P B 1$ was amplified with primer pair VPB1-OX-F/VPB1-OX-R, and then cloned into pCAMBIA1301S by KpnI-XbaI digestion. For overexpression of OsBOP1, the full-length cDNA sequence of OsBOP1 was amplified with primer pair OsBOP1-OX-F/OsBOP1OX-R, and then cloned into pCAMBIA1301S by KpnI-BamHI digestion. Two 20-bp fragments targeting LOC_Os05g38120 were designed to generate VPB1 knockout mutants by using CRISPR/Cas9 vector system [40]. The target fragment was inserted into the binary vector pYLCRISPR/Cas9-MH. The above constructs were introduced into 
Agrobacterium tumefaciens EHA105 and homozygous callus from vpb1 mutuant plant and wild type plant (ZH11), as previously reported [60]. All the primers were listed in Table S4.

\subsection{Total RNA Isolation and qRT-PCR Analyses}

Total RNA was extracted with TRIzol reagent (Invitrogen, Shanghai, China). The $3 \mu \mathrm{g}$ of RNA was treated with RNase-free DNaseI (Invitrogen). Subsequently, we synthesized first-strand cDNA with oligo (dT)18 primer (TaKaRa, Kyoto, Japan) and M-MLV reverse transcriptase (Invitrogen, Shanghai, China). The qRT-PCR was performed with SYBR Green Master MIX (Roche) in a total $10 \mu \mathrm{L}$ reaction system on the Applied Biosystems ViiA 7 Real-Time PCR system according to the manufacturer's instructions. Data were normalized into the internal rice ubiquitin $(U B Q)$ gene. The relative quantification method (2(-Delta Delta CT) ) was used for data analysis. All primers were listed in Table S4.

\subsection{In Situ Hybridization}

Sample fixation and sectioning were performed as described above, followed by hybridization and immunological detection in the previously reported method [61]. The gene-specific primers were used to amplify the probes of VPB1, OSH1, and OsBOP1 by PCR. The forward and reverse primers were fused with T7 and SP6 promoters, respectively. SP6 and T7 RNA polymerases were used to transcribe the antisense and sense probes in vitro, respectively, using the digoxigenin-labeled nucleotide mixture (Sigma-Aldrich, St. Louis, MO, USA).

\subsection{Subcellular Localization}

To construct the subcellular localization plasmids, primers VPB1-pM999-F and VPB1pM999-R with KpnI-XbaI digestion sites were used to amplify the full-length cDNA of VPB1, and then amplified product was inserted into pM999-YFP vector. The obtained constructs were transformed into rice protoplasts isolated from two weeks etiolated seedlings and incubated at $23{ }^{\circ} \mathrm{C}$ for $12 \pm 16 \mathrm{~h}$. After incubation, the fluorescence of transformed protoplasts was observed with a confocal laser scanning microscope (TCS SP2; Leica, Weztlar, Germany).

\subsection{Transcriptional Activity Analysis}

Dual-Luciferase Reporter assay system (Promega, Madison, WI, USA) was used to analyze the transcriptional activity of VPB1 in rice protoplasts prepared from etiolated seedlings [62]. We used the GAL4-responsive vector as a reporter, which was produced by fusing the firefly LUC gene driven by the CaMV $35 S$ promoter, five copies of the GAL4 binding site in tandem, and a minimal TATA box, and used the Renilla luciferase gene driven by Arabidopsis thaliana UBIQUITIN3 promoter as internal control. The full-length coding sequence of VPB1 was amplified using the primers GAL4BD-VPB1-F and GAL4BD-VPB1-R (Table S4) with EcoRI-SalI sites, and the amplified product was inserted into the vector that contained GAL4BD where it acted as an effector. In each transcriptional activity assay, we co-transformed the reporter, effector, and internal control into rice protoplasts in a ratio of 5:5:1 and incubated them at $23{ }^{\circ} \mathrm{C}$ for $12 \pm 16 \mathrm{~h}$. After incubation, the relative luciferase activity was measured in the DLR assay system with the TECAN Infinite M200 microplate reader.

To assess the specific binding ability of $O s B O P 1$ promoter, we prepared rice protoplasts from two-week-old fully green plant of ZH11 variety [63]. We inserted the coding sequence of VPB1 into the NONE vector with the EcoRI-SalI sites to obtain an effector plasmid. Then, we amplified a 2000-bp upstream fragment of the OsBOP1 promoter, and inserted the amplified product into 190-LUC vector with the HindIII sites to construct the OsBOP1: LUC reporter vector. The Renilla luciferase gene driven by CaMV 35S was used as internal control. In each transcriptional activity assay, we co-transformed $5 \mu \mathrm{g}$ of effector plasmid DNA and $5 \mu \mathrm{g}$ of reporter plasmid DNA into rice protoplasts. All primers were presented in Table S4. 


\subsection{RNA-Seq Analysis}

We isolated total RNA from $2 \mathrm{~mm}$ young panicles of WT plants and vpb1 mutant plants. The experiment had three biological replicates. RNA-seq library was constructed and sequenced using DNBSeq at the Wuhan Genome Institute (BGI) (China). The clean reads were mapped to the rice reference genome (Os-Nipponbare-Refrence-IRGSP-1.0, MSU7) using Hisat2 (http://ccb.jhu.edu/software/hisat2/index.shtml (accessed on 27 October 2020). $Q$ value $\leq 0.05$ and fold-change ( $\mid \log 2$ ratio $\mid$ ) $>1.5$ were considered as statistically significantly different. The GO analysis of DEGs was performed using agriGO [64].

\subsection{EMSA}

Promoter OsBOP1 with core motif CATGACAGAT and promoter OsBOP2 with core motif TATGACAGAT were produced by annealing oligonucleotides with biotin 5 '-end labeled OsBOP1-EMSA-F/R, OsBOP2-EMSA-MF/MR, respectively. In each reaction, we incubated $50 \mathrm{fmol}$ biotin-labeled probes with the MBP-VPB1 protein in the binding buffer containing $10 \mu \mathrm{MZnCl}_{2}, 10 \mathrm{mM}$ Tris, $50 \mathrm{mM} \mathrm{KCl}, 1 \mu \mathrm{g} / \mu \mathrm{L}$ poly (dI-dC), $1 \mathrm{mM}$ DTT, $0.05 \%$ NP-40, and $0.1 \%$ BSA, $2.5 \%$ glycerol on ice for 30 min by using the LightShift Chemiluminescent EMSA kit. EMSA was performed as previously reported [61].

\subsection{The Transient Expression System in Tobacco}

To construct the tobacco transformation plasmids, primers PFA1300-BOP1-F/R with KpnI-Sall digestion sites were used to amplify a 2000-bp upstream fragment of the OsBOP1 promoter, and then amplified product was inserted into PFA1300-LUC vector, primers 35S-GFP-VPB1-F/R with KpnI-BamHI digestion sites were used to amplify the full-length cDNA of VPB1, and then amplified product was inserted into 35S-CGFP vector. The vector combination 35S-CGFP-VPB1/PFA1300-LUC-BOP1, 35S-CGFP/PFA1300-LUC-BOP1 were transformed into Nicotiana benthamiana leaves by Agrobacterium, repeated three times, cultured at room temperature for two days, and the whole leaves were injected with $1 \mathrm{mM}$ luciferase substrate. Images were visualized on Tanon-5200 Chemiluminescent Imaging System (Tanon Science and Technology).

\subsection{Accession Numbers}

Sequence data used in this study were downloaded from the Rice Genome Annotation Project website (MSU) and TAIR library. The accession numbers of genes were as follows: VPB1 (LOC_Os05g38120), qSH1 (LOC_Os01g62920), OSH1 (LOC_Os03g51690), OSH15 (LOC_Os07g03770), OSH71 (LOC_Os05g03884), OsBOP1 (LOC_Os01g72020), OsBOP2 (LOC_Os11g04600), OsBOP3 (LOC_Os12g04410), PNY (AT5G02030), BOP1 (AT3G57130), and BOP2 (AT2G41370).

\section{Conclusions and Future Prospects}

In conclusion, we show that a BELL-like homeodomain protein, VPB1, is involved in the regulation of panicle architecture in rice. VPB1 loss-of-function mutants exhibited the clustered primary branch phenotype and the length of rachis was reduced. Map-based cloning revealed that VPB1 is identical to previously reported SH5/RI gene [38,39]. While the $S H 5 / R I$ gene and its protein as an interactor with KNOX protein with key roles in rice panicle development has been reported in gene expression studies, few studies provided a molecular mechanism of the panicle branching patterns in rice based on mutant analysis. This study fills that gap in knowledge and provides evidence that VPB1 regulates the expression of related genes involved in inflorescence meristem development and auxin pathways, and directly inhibits the expression of lateral organ gene OsBOP1, maintaining the balance of inflorescence meristem and lateral meristem development, thereby ensuring the fine arrangement of panicle branches. Therefore, these results indicate that VPB1 is a key gene for the normal arrangement of panicle branches in rice. 
Indeed, VPB1 can interact with OSH1 and OSH15 to form heterodimers, indicating that VPB1 may regulate the panicle branching patterns in rice by functioning as heterodimers with KNOX proteins, but few of their functions have been identified. Is it possible to recruit more proteins after the formation of heterodimers to participate in the regulation of panicle development? We hope that their functions can be revealed in our future studies. In addition, VPB1, as a transcription factor with DNA binding ability, obtained 682 genes containing core sequences by analyzing the promoter sequences of the differential genes. What are its downstream target genes besides OsBOP1 gene? It will be interesting to determine how VPB1 genetically interacts with these genes to regulate rice panicle morphogenesis in future research.

Supplementary Materials: The following are available online at https:/ / www.mdpi.com/article/10 $.3390 /$ ijms22157909/s1.

Author Contributions: Conceptualization, C.W. and M.L.; Methodology, M.L., D.F. and T.X.; Validation, C.W. and M.L.; Formal analysis, C.W., M.L. and D.F.; Investigation, M.L.; Resources, D.F. and T.X.; Data curation, C.W. and M.L.; Writing—original draft preparation, M.L.; Writing-review and editing, C.W. and M.L.; Visualization, M.L.; Supervision, C.W.; Project administration, C.W.; Funding acquisition, C.W. All authors have read and agreed to the published version of the manuscript.

Funding: This work was supported by the National Natural Science Foundation of China (31630054, 31425018, 31821005), and Program for Chinese Outstanding Talents in Agricultural Scientific Research.

Institutional Review Board Statement: Not applicable.

Informed Consent Statement: Not applicable.

Data Availability Statement: The data presented in this study are available on request from the corresponding author.

Acknowledgments: Great gratitude goes to Ping Liu from Foreign Language College, Huazhong Agriculture University, Wuhan, China for her work at English editing and language polishing.

Conflicts of Interest: The authors declare no conflict of interest.

\section{References}

1. Benlloch, R.; Berbel, A.; Serrano-Mislata, A.; Madueno, F. Floral initiation and inflorescence architecture: A comparative view. Ann. Bot. 2007, 100, 659-676. [CrossRef]

2. Gao, X.-Q.; Wang, N.; Wang, X.-L.; Zhang, X.S. Architecture of wheat inflorescence: Insights from rice. Trends Plant Sci. 2019, 24, 802-809. [CrossRef]

3. McSteen, P.; Leyser, O. Shoot branching. Annu. Rev. Plant Biol. 2005, 56, 353-374. [CrossRef] [PubMed]

4. Wang, Y.; Li, J. Molecular basis of plant architecture. Annu. Rev. Plant Biol. 2008, 59, 253-279. [CrossRef]

5. Teo, Z.W.N.; Song, S.; Wang, Y.-Q.; Liu, J.; Yu, H. New insights into the regulation of inflorescence architecture. Trends Plant Sci. 2014, 19, 158-165. [CrossRef] [PubMed]

6. Bortiri, E.; Hake, S. Flowering and determinacy in maize. J. Exp. Bot. 2007, 58, 909-916. [CrossRef]

7. Ikeda, K.; Sunohara, H.; Nagato, Y. Developmental course of inflorescence and spikelet in rice. Breed. Sci. 2004, 54, 147-156. [CrossRef]

8. Itoh, J.-I.; Nonomura, K.-I.; Ikeda, K.; Yamaki, S.; Inukai, Y.; Yamagishi, H.; Kitano, H.; Nagato, Y. Rice plant development: From zygote to spikelet. Plant Cell Physiol. 2005, 46, 23-47. [CrossRef]

9. Xing, Y.; Zhang, Q. Genetic and molecular bases of rice yield. Annu. Rev. Plant Biol. 2010, 61, 421-442. [CrossRef] [PubMed]

10. Oikawa, T.; Kyozuka, J. Two-step regulation of LAX PANICLE1 protein accumulation in axillary meristem formation in rice. Plant Cell 2009, 21, 1095-1108. [CrossRef]

11. Tabuchi, H.; Zhang, Y.; Hattori, S.; Omae, M.; Shimizu-Sato, S.; Oikawa, T.; Qian, Q.; Nishimura, M.; Kitano, H.; Xie, H.; et al. LAX PANICLE2 of rice encodes a novel nuclear protein and regulates the formation of axillary meristems. Plant Cell 2011, 23, 3276-3287. [CrossRef]

12. Ikeda, K.; Ito, M.; Nagasawa, N.; Kyozuka, J.; Nagato, Y. Rice ABERRANT PANICLE ORGANIZATION 1, encoding an F-box protein, regulates meristem fate. Plant J. 2007, 51, 1030-1040. [CrossRef]

13. Ikeda-Kawakatsu, K.; Maekawa, M.; Izawa, T.; Itoh, J.-I.; Nagato, Y. ABERRANT PANICLE ORGANIZATION $2 /$ RFL, the rice ortholog of Arabidopsis $L E A F Y$, suppresses the transition from inflorescence meristem to floral meristem through interaction with APO1. Plant J. 2012, 69, 168-180. [CrossRef] 
14. Suzaki, T.; Sato, M.; Ashikari, M.; Miyoshi, M.; Nagato, Y.; Hirano, H.-Y. The gene FLORAL ORGAN NUMBER1 regulates floral meristem size in rice and encodes a leucine-rich repeat receptor kinase orthologous to Arabidopsis CLAVATA1. Development 2004, 131, 5649-5657. [CrossRef] [PubMed]

15. Suzaki, T.; Toriba, T.; Fujimoto, M.; Tsutsumi, N.; Kitano, H.; Hirano, H.-Y. Conservation and diversification of meristem maintenance mechanism in oryza sativa: Function of the FLORAL ORGAN NUMBER2 gene. Plant Cell Physiol. 2006, 47, 1591-1602. [CrossRef]

16. Kwon, Y.; Yu, S.-I.; Park, J.-H.; Li, Y.; Han, J.-H.; Alavilli, H.; Cho, J.-I.; Kim, T.-H.; Jeon, J.-S.; Lee, B.-H. OsREL2, a rice TOPLESS homolog functions in axillary meristem development in rice inflorescence. Plant Biotechnol. Rep. 2012, 6, 213-224. [CrossRef]

17. Yoshida, A.; Ohmori, Y.; Kitano, H.; Taguchi-Shiobara, F.; Hirano, H.-Y. ABERRANT SPIKELET AND PANICLE1, encoding a TOPLESS-related transcriptional co-repressor, is involved in the regulation of meristem fate in rice. Plant J. 2012, 70, 327-339. [CrossRef]

18. Suzuki, C.; Tanaka, W.; Hirano, H.-Y. Transcriptional corepressor ASP1 and CLV-like signaling regulate meristem maintenance in Rice. Plant Physiol. 2019, 180, 1520-1534. [CrossRef] [PubMed]

19. Tanaka, W.; Ohmori, Y.; Ushijima, T.; Matsusaka, H.; Matsushita, T.; Kumamaru, T.; Kawano, S.; Hirano, H.-Y. Axillary meristem formation in rice requires the WUSCHEL ortholog TILLERS ABSENT1. Plant Cell 2015, 27, 1173-1184. [CrossRef] [PubMed]

20. Yoshida, A.; Sasao, M.; Yasuno, N.; Takagi, K.; Daimon, Y.; Chen, R.; Yamazaki, R.; Tokunaga, H.; Kitaguchi, Y.; Sato, Y.; et al. TAWAWA1, a regulator of rice inflorescence architecture, functions through the suppression of meristem phase transition. Proc. Natl. Acad. Sci. USA 2013, 110, 767-772. [CrossRef] [PubMed]

21. Hamant, O.; Pautot, V. Plant development: A TALE story. C.R. Biol. 2010, 333, 371-381. [CrossRef] [PubMed]

22. Bhatt, A.M.; Etchells, J.P.; Canales, C.; Lagodienko, A.; Dickinson, H. VAAMANA-a BEL1-like homeodomain protein, interacts with KNOX proteins BP and STM and regulates inflorescence stem growth in Arabidopsis. Gene 2004, 328, 103-111. [CrossRef] [PubMed]

23. Byrne, M.E.; Groover, A.T.; Fontana, J.R.; Martienssen, R.A. Phyllotactic pattern and stem cell fate are determined by the Arabidopsis homeobox gene BELLRINGER. Development 2003, 130, 3941-3950. [CrossRef]

24. Kanrar, S.; Bhattacharya, M.; Arthur, B.; Courtier, J.; Smith, H.M.S. Regulatory networks that function to specify flower meristems require the function of homeobox genes PENNYWISE and POUND-FOOLISH in Arabidopsis. Plant J. 2008, 54, 924-937. [CrossRef]

25. Khan, M.; Ragni, L.; Tabb, P.; Salasini, B.C.; Chatfield, S.; Datla, R.; Lock, J.; Kuai, X.; Despres, C.; Proveniers, M.; et al. Repression of lateral organ boundary genes by PENNYWISE and POUND-FOOLISH is essential for meristem maintenance and flowering in Arabidopsis. Plant Physiol. 2015, 169, 2166-2186. [CrossRef]

26. Roeder, A.H.K.; Ferrándiz, C.; Yanofsky, M.F. The role of the REPLUMLESS homeodomain protein in patterning the Arabidopsis fruit. Curr. Biol. 2003, 13, 1630-1635. [CrossRef] [PubMed]

27. Smith, H.M.S.; Campbell, B.C.; Hake, S. Competence to respond to floral inductive signals requires the homeobox genes PENNYWISE and POUND-FOOLISH. Curr. Biol. 2004, 14, 812-817. [CrossRef]

28. Ung, N.; Lal, S.; Smith, H.M.S. The role of PENNYWISE and POUND-FOOLISH in the maintenance of the shoot apical meristem in Arabidopsis. Plant Physiol. 2011, 156, 605-614. [CrossRef]

29. Yu, L.; Patibanda, V.; Smith, H.M.S. A novel role of BELL1-like homeobox genes, PENNYWISE and POUND-FOOLISH, in floral patterning. Planta 2008, 229, 693-707. [CrossRef]

30. Smith, H.M.S.; Hake, S. The interaction of two homeobox genes, BREVIPEDICELLUS and PENNYWISE, regulates internode patterning in the Arabidopsis inflorescence. Plant Cell 2003, 15, 1717-1727. [CrossRef]

31. Peaucelle, A.; Louvet, R.; Johansen, J.N.; Salsac, F.; Morin, H.; Fournet, F.; Belcram, K.; Gillet, F.; Hofte, H.; Laufs, P.; et al. The transcription factor BELLRINGER modulates phyllotaxis by regulating the expression of a pectin methylesterase in Arabidopsis. Development 2011, 138, 4733-4741. [CrossRef]

32. Kanrar, S.; Onguka, O.; Smith, H.M.S. Arabidopsis inflorescence architecture requires the activities of KNOX-BELL homeodomain heterodimers. Planta 2006, 224, 1163-1173. [CrossRef]

33. Rutjens, B.; Bao, D.; van Eck-Stouten, E.; Brand, M.; Smeekens, S.; Proveniers, M. Shoot apical meristem function in Arabidopsis requires the combined activities of three BEL1-like homeodomain proteins. Plant J. 2009, 58, 641-654. [CrossRef] [PubMed]

34. Bencivenga, S.; Serrano-Mislata, A.; Bush, M.; Fox, S.; Sablowski, R. Control of oriented tissue growth through repression of organ boundary genes promotes stem morphogenesis. Dev Cell. 2016, 39, 198-208. [CrossRef]

35. Tsuda, K.; Abraham-Juarez, M.-J.; Maeno, A.; Dong, Z.; Aromdee, D.; Meeley, R.; Shiroishi, T.; Nonomura, K.-i.; Hake, S. KNOTTED1 cofactors, BLH12 and BLH14, regulate internode patterning and vein anastomosis in maize. Plant Cell 2017, 29, 1105-1118. [CrossRef] [PubMed]

36. Konishi, S.; Izawa, T.; Lin, S.Y.; Ebana, K.; Fukuta, Y.; Sasaki, T.; Yano, M. An SNP caused loss of seed shattering during rice domestication. Science 2006, 312, 1392-1396. [CrossRef] [PubMed]

37. Yoon, J.; Cho, L.-H.; Kim, S.L.; Choi, H.; Koh, H.-J.; An, G. The BEL1-type homeobox gene SH5 induces seed shattering by enhancing abscission-zone development and inhibiting lignin biosynthesis. Plant J. 2014, 79, 717-728. [CrossRef] [PubMed]

38. Yoon, J.; Cho, L.-H.; Antt, H.W.; Koh, H.-J.; An, G. KNOX protein OSH15 induces grain shattering by repressing lignin biosynthesis genes. Plant Physiol. 2017, 174, 312-325. [CrossRef] [PubMed] 
39. Ikeda, T.; Tanaka, W.; Toriba, T.; Suzuki, C.; Maeno, A.; Tsuda, K.; Shiroishi, T.; Kurata, T.; Sakamoto, T.; Murai, M.; et al. BELL1-like homeobox genes regulate inflorescence architecture and meristem maintenance in rice. Plant J. 2019, 98, 465-478. [CrossRef]

40. Ma, X.; Liu, Y.G. CRISPR/Cas9-based multiplex genome editing in monocot and dicot plants. Curr. Protoc. Mol. Biol 2016, 115, 31-36. [CrossRef]

41. Gómez-Mena, C.; Sablowski, R. ARABIDOPSIS THALIANA HOMEOBOX GENE1 establishes the basal boundaries of shoot organs and controls stem growth. Plant Cell 2008, 20, 2059-2072. [CrossRef] [PubMed]

42. He, L.; Liu, Y.; He, H.; Liu, Y.; Qi, J.; Zhang, X.; Li, Y.; Mao, Y.; Zhou, S.; Zheng, X.; et al. A molecular framework underlying the compound leaf pattern of Medicago truncatula. Nat. Plants. 2020, 6, 511-521. [CrossRef] [PubMed]

43. Chou, K.-C.; Shen, H.-B. Cell-PLoc: A package of Web servers for predicting subcellular localization of proteins in various organisms. Nat. Protoc. 2008, 3, 153-162. [CrossRef]

44. Hu, Y.; Liang, W.; Yin, C.; Yang, X.; Ping, B.; Li, A.; Jia, R.; Chen, M.; Luo, Z.; Cai, Q.; et al. Interactions of OsMADS1 with floral homeotic genes in rice flower development. Mol. Plant 2015, 8, 1366-1384. [CrossRef]

45. Itoh, J.-I.; Kitano, H.; Matsuoka, M.; Nagato, Y. SHOOT ORGANIZATION genes regulate shoot apical meristem organization and the pattern of leaf primordium initiation in rice. Plant Cell 2000, 12, 2161-2174. [CrossRef]

46. Wu, Y.; Wang, Y.; Mi, X.-F.; Shan, J.-X.; Li, X.-M.; Xu, J.-L.; Lin, H.-X. The QTL GNP1 encodes GA20ox1, which increases grain number and yield by increasing cytokinin activity in rice panicle meristems. PLoS Genet. 2016, 12, e1006386. [CrossRef] [PubMed]

47. He, Y.; Yan, L.; Ge, C.; Yao, X.-F.; Han, X.; Wang, R.; Xiong, L.; Jiang, L.; Liu, C.-M.; Zhao, Y. PINOID is required for formation of the stigma and style in rice. Plant Physiol. 2019, 180, 926-936. [CrossRef] [PubMed]

48. Jiang, L.; Ma, X.; Zhao, S.; Tang, Y.; Liu, F.; Gu, P.; Fu, Y.; Zhu, Z.; Cai, H.; Sun, C.; et al. The APETALA2-like transcription factor SUPERNUMERARY BRACT controls rice seed shattering and seed size. Plant Cell 2019, 31, 17-36. [CrossRef] [PubMed]

49. Andrés, F.; Romera-Branchat, M.; Martínez-Gallegos, R.; Patel, V.; Schneeberger, K.; Jang, S.; Altmüller, J.; Nürnberg, P.; Coupland, G. Floral induction in Arabidopsis thaliana by FLOWERING LOCUS T requires direct repression of BLADE-ON-PETIOLE genes by homeodomain protein PENNYWISE. Plant Physiol. 2015, 169, 2187-2199. [CrossRef] [PubMed]

50. Chow, C.-N.; Lee, T.-Y.; Hung, Y.-C.; Li, G.-Z.; Tseng, K.-C.; Liu, Y.-H.; Kuo, P.-L.; Zheng, H.-Q.; Chang, W.-C. PlantPAN3.0: A new and updated resource for reconstructing transcriptional regulatory networks from ChIP-seq experiments in plants. Nucleic Acids Res. 2019, 47, 1155-1163. [CrossRef]

51. Grant, C.E.; Bailey, T.L.; Noble, W.S. FIMO: Scanning for occurrences of a given motif. Bioinformatics 2011, 27, 1017-1018. [CrossRef]

52. Simonini, S.; Stephenson, P.; Østergaard, L. A molecular framework controlling style morphology in Brassicaceae. Development 2018, 145, dev158105. [CrossRef]

53. Wu, Y.; Fu, Y.; Zhao, S.; Gu, P.; Zhu, Z.; Sun, C.; Tan, L. CLUSTERED PRIMARY BRANCH 1, a new allele of DWARF11, controls panicle architecture and seed size in rice. Plant Biotechnol. J. 2015, 14, 377-386. [CrossRef] [PubMed]

54. Khan, M.; Xu, H.; Hepworth, S.R. BLADE-ON-PETIOLE genes: Setting boundaries in development and defense. Plant Sci. 2014, 215, 157-171. [CrossRef]

55. Jost, M.; Taketa, S.; Mascher, M.; Himmelbach, A.; Yuo, T.; Shahinnia, F.; Rutten, T.; Druka, A.; Schmutzer, T.; Steuernagel, B.; et al. A homolog of Blade-On-Petiole 1 and 2 (BOP1/2) controls internode length and homeotic changes of the barley inflorescence. Plant Physiol. 2016, 171, 1113-1127. [CrossRef] [PubMed]

56. Xu, C.; Park, S.J.; van Eck, J.; Lippman, Z.B. Control of inflorescence architecture in tomato by BTB/POZ transcriptional regulators. Genes Dev. 2016, 30, 2048-2061. [CrossRef]

57. Toriba, T.; Tokunaga, H.; Shiga, T.; Nie, F.; Naramoto, S.; Honda, E.; Tanaka, K.; Taji, T.; Itoh, J.-I.; Kyozuka, J. BLADE-ONPETIOLE genes temporally and developmentally regulate the sheath to blade ratio of rice leaves. Nat. Commun. 2019, 10, 619-632. [CrossRef] [PubMed]

58. Ragni, L.; Belles-Boix, E.; Günl, M.; Pautot, V. Interaction of KNAT6 and KNAT2 with BREVIPEDICELLUS and PENNYWISE in Arabidopsis inflorescences. Plant Cell 2008, 20, 888-900. [CrossRef]

59. Liu, Y.; You, S.; Taylor-Teeples, M.; Li, W.L.; Schuetz, M.; Brady, S.M.; Douglas, C.J. BEL1-LIKE HOMEODOMAIN6 and KNOTTED ARABIDOPSIS THALIANA7 interact and regulate secondary cell wall formation via repression of REVOLUTA. Plant Cell 2014, 26, 4843-4861. [CrossRef] [PubMed]

60. Wu, C.; Li, X.; Yuan, W.; Chen, G.; Kilian, A.; Li, J.; Xu, C.; Li, X.; Zhou, D.-X.; Wang, S.; et al. Development of enhancer trap lines for functional analysis of the rice genome. Plant J. 2003, 35, 418-427. [CrossRef] [PubMed]

61. Wang, L.; Sun, S.; Jin, J.; Fu, D.; Yang, X.; Weng, X.; Xu, C.; Li, X.; Xiao, J.; Zhang, Q. Coordinated regulation of vegetative and reproductive branching in rice. Proc. Natl. Acad. Sci. USA 2015, 112, 15504-15509. [CrossRef] [PubMed]

62. Hao, Y.-J.; Song, Q.-X.; Chen, H.-W.; Zou, H.-F.; Wei, W.; Kang, X.-S.; Ma, B.; Zhang, W.-K.; Zhang, J.-S.; Chen, S.-Y. Plant NAC-type transcription factor proteins contain a NARD domain for repression of transcriptional activation. Planta 2010, 232, 1033-1043. [CrossRef] [PubMed]

63. Bart, R.; Chern, M.; Park, C.J.; Bartley, L.; Ronald, P.C. A novel system for gene silencing using siRNAs in rice leaf and stem-derived protoplasts. Plant Methods 2006, 2, 13. [CrossRef] [PubMed]

64. Tian, T.; Liu, Y.; Yan, H.; You, Q.; Yi, X.; Du, Z.; Xu, W.; Su, Z. agriGO v2.0: A GO analysis toolkit for the agricultural community, 2017 update. Nucleic Acids Res. 2017, 45, 122-129. [CrossRef] [PubMed] 